\title{
1 Survival and detection of bivalve transmissible neoplasia from the soft-shell clam Mya arenaria
}

2 (MarBTN) in seawater

3

4 Rachael M. Giersch ${ }^{1}$, Samuel F.M. Hart ${ }^{1,2}$, Satyatejas G. Reddy ${ }^{3,4}$, Marisa A. Yonemitsu ${ }^{1,2}$, María J.

5 Orellana Rosales ${ }^{3,5}$, Madelyn Korn ${ }^{1,6}$, Brook M. Geleta ${ }^{1,7}$, Peter D. Countway ${ }^{3}$, José A. Fernández

6 Robledo $^{3}$, Michael J. Metzger ${ }^{1,2 *}$

7

\section{AUTHOR INFORMATION}

91 Pacific Northwest Research Institute, Seattle, WA 98122, USA

102 Molecular and Cellular Biology Program, University of Washington, Seattle, WA 98195, USA

113 Bigelow Laboratory for Ocean Sciences, East Boothbay, ME 04544, USA

124 University of Georgia, Athens, GA 30602, USA

135 Southern Maine Community College, South Portland, ME 04106, USA

146 Tulane University, New Orleans, LA 70118, USA

157 Macalester College, Saint Paul, MN 55105, USA

$16 *$ Corresponding author: metzgerm@pnri.org

\section{ABSTRACT}

19 Many pathogens can cause cancer, but cancer itself does not normally act as an infectious agent.

20 However, transmissible cancers have been found in a few cases in nature: in Tasmanian devils, dogs, and

21 several bivalve species. The transmissible cancers in dogs and devils are known to spread through direct 
22 physical contact, but the exact route of transmission of bivalve transmissible neoplasia (BTN) has not yet

23 been confirmed. It has been hypothesized that cancer cells could be released by diseased animals and

24 spread through the water column to infect/engraft into other animals. To test the feasibility of this

25 proposed mechanism of transmission, we tested the ability of BTN cells from the soft-shell clam (Mya

26 arenaria BTN, or MarBTN) to survive in artificial seawater. We found that BTN cells are highly sensitive

27 to salinity, with acute toxicity at salinity levels lower than those found in their environment. BTN cells

28 also survive longer at lower temperatures, with $>48 \%$ of cells surviving a week in seawater at

29 temperatures from $4^{\circ} \mathrm{C}$ to $16^{\circ} \mathrm{C}$, and $49 \%$ surviving for more than two weeks at $4^{\circ} \mathrm{C}$. With one clam

30 donor, living cells were observed for more than eight weeks at $4{ }^{\circ} \mathrm{C}$. We also used qPCR of environmental

31 DNA (eDNA) to detect the presence of BTN-specific DNA in the environment. We observed release of

32 BTN-specific DNA into the water of aquaria from tanks with highly BTN-positive clams, and we detected

33 BTN-specific DNA in seawater samples collected from BTN-endemic areas, although the level detected

34 was much lower. Overall, these data show that BTN cells can survive well in seawater, and they are

35 released into the water by diseased animals, supporting the hypothesis that BTN is spread from animal-to-

36 animal by cells through seawater.

\section{KEYWORDS}

39 transmissible cancer, contagious cancer, bivalve transmissible neoplasia, BTN, MarBTN, soft-shell clam,

40 Mya arenaria, disseminated neoplasia

\section{INTRODUCTION}

Most cancer stays with the organism from which it came, arising and dying within a single host,

44 but in a few cases, cancer has evolved to transmit from one animal to the next, acting as a pathogen as

45 well as a cancer. The first naturally transmissible cancers to be found were the canine transmissible 
venereal tumor (CTVT) $(1,2)$ and the Tasmanian devil facial tumor disease (DFTD) $(3,4)$. More

47 recently, a leukemia-like disease in multiple bivalve species, called disseminated neoplasia (DN) or hemic neoplasia, was shown to be a transmissible cancer (5). DN is characterized by proliferation of nonadherent, rounded, polyploid neoplastic cells primarily found in the hemolymph of infected bivalves, which disseminate into tissues during later stages of this typically fatal disease $(6,7)$. The disease had been reported for many decades, although the etiology was unknown. Retroviruses or pollution had been thought to be the likely causes $(8,9)$, although two early reports had suggested that it could be due to infectious spread of cancer cells (Sunila et al. 1998 and James Moore's 1993 Ph.D. Dissertation (10, 11)).

54 DN was first confirmed to be a transmissible cancer in soft-shell clams (Mya arenaria) (5), and later, multiple independent lineages of transmissible cancer were identified in multiple species worldwide (12). To date, seven lineages of the bivalve transmissible neoplasia (BTN) in eight bivalve species have been reported $(5,12-17)$. In many cases, the BTN that circulates in each species has arisen from a member of that same species. However, increasing cases of cross-species transmission have been reported (a lineage from Venerupis corrugata to Polititapes aureus and a single lineage of Mytilus BTN now found in four Mytilus species). Furthermore, multiple independent lineages of BTN have been found to circulate within the same species (as in Cerastoderma edule and Mytilus trossulus). In soft-shell clams, all analyzed samples of DN since the confirmation of cancer transmission so far have proven to be a part of one lineage of BTN that arose from a single founder soft-shell clam and has since spread throughout populations along the North American East Coast between Prince Edward Island (Canada) and New York (USA). DN has been reported in M. arenaria as early as $1978(18,19)$ and it has been observed as far south as Chesapeake Bay, Maryland, USA $(9,20,21)$. While it is likely that these earlier reports of DN in

67 soft-shell clams represent the same BTN lineage observed today, this cannot yet be confirmed. biting, respectively), but most adult bivalves are sessile or with limited mobility, without direct contact of 
71 evidence clearly shows that cancers in different individual bivalves do not match the genotypes of their

72 hosts and that cancers in different individuals, separated by large distances (and in some cases in different

73 species and different oceans), are nearly identical, so the cancer lineages must transmit through some

74 alternate mechanism. The most likely route of transmission is release of the BTN cells into the seawater

75 and uptake of the cells by naïve animals through filter feeding. For this to occur, BTN cells need to be

76 released from animals and survive in seawater long enough to engraft into a naïve individual.

A previous report (the first known to propose a transmissible cancer hypothesis for DN in

81 (Mya arenaria BTN, or MarBTN) to survive in seawater. We determined the effect of salinity, pH, and

82 temperature on their short-term survival in artificial seawater (ASW), and we determined how long the

83 cells can survive at varying temperatures. We additionally tested whether BTN cells can be detected in

84 seawater through the analysis of environmental DNA (eDNA) collected from both laboratory and field

85 settings. Our findings provide further validation supporting seawater-based transmission of BTN in the

86 wild.

MATERIALS AND METHODS

\section{Collection of clams and MarBTN cells}

90 Soft-shell clams (M. arenaria) were collected by commercial sources from multiple locations in Maine,

91 USA (Table S1), and animals were screened for high levels of DN as before (5). Animals were housed in

$921 \times$ ASW (36 g / L Instant Ocean, Blacksburg, VA, USA), in aerated aquaria, supplemented 2-3 times

93 weekly with PhytoFeast or LPB Frozen Shellfish Diet (Reed Mariculture, Campbell, CA, USA).

94 Approximately $0.5-1 \mathrm{~mL}$ of hemolymph was collected from the pericardial sinus of each animal using a 
0.5 in 26-gauge needle on a $3 \mathrm{~mL}$ syringe. Several drops were placed in a well of a 96-well plate and incubated at $4-10^{\circ} \mathrm{C}$ for 1 hour to allow the cells to settle. Wells were screened for clams with high levels of BTN based on morphological differences between healthy hemocytes and BTN cells on an inverted phase-contrast microscope. Only animals with $\geq 75 \%$ of cancer cells in their hemolymph were used in survival experiments.

\section{Counting live cells in artificial seawater}

We used the alternate vital dye, erythrosine B (MilliporeSigma, Burlington, MA, USA) to stain samples to discriminate live and dead cells during counting. This dye is soluble throughout all salinities used in this study. To count live cells, $10 \mu \mathrm{L}$ of ASW containing cells were mixed 1:1 with $2 \times$ erythrosine B solution $(10 \mu \mathrm{g} / \mathrm{mL}$, dissolved in PBS4, which is PBS plus $400 \mathrm{mM} \mathrm{NaCl}$ to approximate marine salinity). After $10 \mathrm{~min}$ at room temperature, live cells were counted manually on a hemocytometer, counting only rounded, refractive cells that exclude dye.

\section{Short-term cell survival assays}

For short-term MarBTN cell survival assays, hemolymph was collected from heavily neoplastic animals, and allowed to sit on a $6 \mathrm{~cm}$ tissue culture dish or 24 -well plate at $4{ }^{\circ} \mathrm{C}$ for one hour to allow any healthy hemocytes to adhere to the dish so that they could be removed. Non-adherent cells were then removed and spun down at $500 \times \mathrm{g}$ for $10 \mathrm{~min}$ at $4{ }^{\circ} \mathrm{C}$. Hemolymph was removed, and cells were resuspended in 1× ASW: filter-sterilized Instant Ocean with no additives, $36 \mathrm{~g} / \mathrm{L}$, specific gravity (sg) 1.023, and pH 7.93. For salinity, cells were diluted to an approximate concentration of $1 \times 10^{6}$ cells $/ \mathrm{mL}$, and $20 \mu \mathrm{L}$ of cells were added to $180 \mu \mathrm{L}$ of ASW with varying concentrations of Instant Ocean, from 0 to $2 \times$ the normal salinity level (with sg measured by a refractometer) and placed in wells of a 96 -well plate at $16^{\circ} \mathrm{C}$.

Cell counts at 4 hours were normalized to expected concentration calculated pre-dilution, as cell death in low salt was too rapid to allow for counting after dilution. For $\mathrm{pH}$, cells were aliquoted into one tube for each condition, spun a second time, and resuspended in $200 \mu \mathrm{L}$ of ASW with different $\mathrm{pH}$ (3.8-9.3, 
modified with $2 \mathrm{M} \mathrm{NaOH}$ or $3 \mathrm{~N} \mathrm{HCl}$ ), with a target of $1 \times 10^{6}$ cell/mL, and put into wells of a 96 -well

plate. For temperature, the cells were resuspended in $400 \mu \mathrm{L}$ of $1 \times \mathrm{ASW}$ (sg 1.023, pH 7.93) and placed

121 in wells of a 24 -well plate at the indicated temperatures $\left(4-37^{\circ} \mathrm{C}\right)$. For $\mathrm{pH}$ and temperature, cell counts at

122 time zero were used to normalize cell survival.

Long-term cell survival assays

124 For long-term cell survival, penicillin/streptomycin (1×, GenClone, Genesee Scientific, El Cahon, CA,

125 USA) and voriconazole (1 mM final concentration, Acros Organics, Thermo Fisher Scientific, Waltham,

126 MA, USA) was added to ASW. Other antimicrobial drugs were tested (e.g., moxifloxacin, doxycycline,

127 metronidazole, and triclosan) but were not found to reduce contaminants at a concentration that was non-

128 toxic to BTN cells. Cells were collected as above and resuspended in $400 \mu \mathrm{L} 1 \times$ ASW with

129 penicillin/streptomycin/voriconazole, in wells of a 48 -well plate, at $2 \times 10^{5}-2 \times 10^{6}$ cells $/ \mathrm{mL}$. After each

130 timepoint, the volume was measured by pipette, and ASW with antimicrobial drugs was added to replace

131 the media removed for cell counting and lost due to evaporation. Live cell counts at each timepoint were

132 normalized by live cell counts at time zero to calculate survival, and the normalization value was

133 multiplied by 0.975 after each additional timepoint to reflect the removal of $10 \mu \mathrm{L}$ of cells from the

134 original $400 \mu \mathrm{L}$ sample.

\section{eDNA extraction from aquaria}

136 Animals were maintained at approximately $10^{\circ} \mathrm{C}$ in individual tanks in $1 \mathrm{~L}$ of $1 \times \mathrm{ASW}$, with constant

137 aeration. $24 \mathrm{hrs}$ prior to water collection, the entire volume of the tank water was replaced. Each day for

138 three days, $250 \mathrm{~mL}$ of each water sample was collected, and the entire tank water was replaced, so that

139 each sampling is from water with $24 \mathrm{hrs}$ of exposure to a single clam. Water samples were vacuum

140 filtered through a $47 \mathrm{~mm} 0.45 \mu \mathrm{m}$ cellulose nitrate filter. Using forceps, the filtered sample/paper was

141 folded small enough to fit into a $2 \mathrm{~mL}$ tube and frozen at $-80^{\circ} \mathrm{C}$ until extraction was performed. 
142

143

144

145

146

147

148

149

150

151

152

153

154

155

156

157

158

159

160

161

162

163

164

165

166

Extraction protocol was modified from Renshaw et al. (22). Briefly, $900 \mu \mathrm{L} \mathrm{CTAB}$ buffer (2\% CTAB w/v, $20 \mathrm{mM}$ EDTA, $100 \mathrm{mM}$ Tris-HCl, and $1.4 \mathrm{M} \mathrm{NaCl}$, in water) was added to the filter, and the tubes were incubated at $65^{\circ} \mathrm{C}$ for $30 \mathrm{~min}$. Tubes were spun to collect the sample in the bottom of the tube and $900 \mu \mathrm{L}$ chloroform:isoamyl alcohol (24:1) was added, followed by shaking or vortexing. Tubes were spun for $5 \mathrm{~min}$ at $15,000 \times \mathrm{g}$, and the $700-850 \mu \mathrm{L}$ aqueous layer was transferred to a new tube with 700 $\mu \mathrm{L}$ chloroform. This was shaken and spun as before and the $\sim 700 \mu \mathrm{L}$ aqueous layer was transferred to a new tube with $700 \mu \mathrm{L}$ cold isopropanol and $24 \mu \mathrm{L} 5 \mathrm{M} \mathrm{NaCl} .4 .67 \mu \mathrm{L}$ glycogen blue was added to ensure visibility of the pellet, and samples were allowed to precipitate overnight at -20 to $-30^{\circ} \mathrm{C}$. DNA was spun for $10 \mathrm{~min}$ at $15,000 \times \mathrm{g}$ and the liquid removed by pipette. $500 \mu \mathrm{L}$ of $75 \%$ ethanol was slowly added and poured off. DNA pellets were air dried and resuspended in $100 \mu \mathrm{L}$ Buffer EB (Qiagen, Hilden, Germany).

\section{Seawater collection and extraction of MarBTN eDNA}

Seawater samples were collected from surface water overlying clam-flats in Maine by filling a single 4liter acid-washed (5\% HCl) HDPE bottle from each location (Quahog Bay Dam, June 6, 2021, 43.812541, -69.896802; Gurnet Landing, June 6, 2021, 43.853734, -69.898677; and Long Cove, June 13, 2021, 43.777156, -69.958582). Sample bottles were stored in a cooler with ice packs until delivery to Bigelow Laboratory within 24 hours of collection. Triplicate sub-samples of $500 \mathrm{~mL}$ seawater were filtered from each bottle onto $47 \mathrm{~mm}$ diameter, $0.2 \mu \mathrm{m}$ Supor filters (Pall Corp., Ann Arbor, MI, USA) to collect environmental DNA. Filters were rolled and placed in $4.5 \mathrm{~mL}$ cryovials (USA Scientific, Ocala, FL, USA) for storage at $-80^{\circ} \mathrm{C}$ until DNA extraction. Filters were rolled to ensure that the particle-bearing filter surface faced inward and that the filter would unfurl when it was transferred to a DNA extraction tube.

Environmental DNA was extracted from the Supor filters using the DNeasy PowerWater kit (Qiagen). Frozen filters were transferred from the cryovials to the $5 \mathrm{~mL}$ PowerWater bead tubes and $1 \mathrm{~mL}$ of warmed $\left(55^{\circ} \mathrm{C}\right) \mathrm{PW} 1$ solution was added. Bead tubes containing a filter, PW1 solution and garnet beads were vortexed for 30 min on a Vortex Genie IIT (Scientific Industries, Bohemia, NY, USA) using a 15 
$\mathrm{mL}$ tube adapter. After the bead-beating step, the crude cell lysate, extracted Supor filter, and most of the beads were tapped into the barrel of a sterile $10 \mathrm{~mL}$ syringe held over a $2 \mathrm{~mL}$ Eppendorf DNA LoBind tube to catch sample lysate. The syringe's plunger was inserted a short way into the syringe barrel before the syringe assembly was flipped upright to purge air. The syringe assembly was inverted over the $2 \mathrm{~mL}$

171 LoBind tube for a second time, and the remaining lysate was pressed out of the bead and filter slurry. The

172 volume of this crude sample lysate was recorded, and the remainder of the DNA extraction procedure

173 followed the kit protocol. Extracted DNA samples were stored in DNA LoBind tubes at $-20^{\circ} \mathrm{C}$ until

174 analysis by qPCR.

\section{qPCR of hemocyte DNA and eDNA}

To quantify the presence of neoplastic DNA in a hemolymph genomic DNA or eDNA sample, allele-

177 specific qPCR was performed using four sets of primers (Table S2). The primary locus was a MarBTN-

178 specific insertion of the LTR-retrotransposon Steamer at the N1N2 gene. A MarBTN-specific primer pair

179 targeting this insertion junction amplifies $1 / 2$ the total amount of N1N1 alleles in a cancer cell (as the

180 insertion is in two of four copies of the gene in a tetraploid region) and a primer pair in a conserved

181 region of the N1N2 ORF nearby quantifies the total copies of the N1N2 locus present. The ratio of the two

182 can be used to determine the fraction of clam hemolymph made up of MarBTN cells. A single plasmid

183 (pCR-SteamerLTR-N1N2) was used for the standard curve. It was made by cloning the Steamer-N1N2

184 amplicon, amplified from genomic DNA of MarBTN cells (Zero Blunt TOPO PCR cloning kit,

185 Invitrogen, Waltham, MA). The secondary marker was a different MarBTN-specific Steamer integration

186 site, termed HL03 (23). A plasmid was cloned which includes both the HL03 locus and a separate

187 conserved region of the EF1 $\alpha$ gene as a control (pIMHL03c2-EF1 $\alpha$ ). Primers used for cloning control

188 plasmids are listed in Table S2, and sequences have been submitted to GenBank. The plasmid

189 concentration was measured (Qubit, Thermo Fisher Scientific) and copy number per $\mu \mathrm{L}$ was calculated

190 based on the plasmid sizes. Plasmids were linearized with $0.25 \mu \mathrm{L}$ of NotI-HF (NEB, Ipswitch, MA,

$191 \mathrm{USA}$ ) for $30 \mathrm{~min}$ at $37^{\circ} \mathrm{C}$ in a $20 \mu \mathrm{L}$ reaction at $1 \times 10^{10}$ copies $/ \mu \mathrm{L}$, heat-inactivated $20 \mathrm{~min}$ at $65^{\circ} \mathrm{C}$, then 
192 diluted to $1 \times 10^{9}$ with $180 \mu \mathrm{L}$ Buffer AE (Qiagen). Standard curves were prepared from $1 \times 10^{7}$

193 copies/rxn to $1 \times 10^{1}$ copies/rxn. For aquaria samples, $2 \mu \mathrm{L}$ of extracted eDNA was run in $10 \mu \mathrm{L}$

194 reactions on a StepOnePlus real-time PCR cycler (Applied Biosystems, Waltham, MA, USA). For field

195 eDNA samples, $4 \mu \mathrm{L}$ of eDNA was used in a $20 \mu \mathrm{L}$ reaction for increased sensitivity. Reactions were run

196 as follows: $95^{\circ} \mathrm{C}$ for $2 \mathrm{~min}, 40$ cycles of $95^{\circ} \mathrm{C}$ for $15 \mathrm{~s}$ and $60^{\circ} \mathrm{C}$ for $30 \mathrm{~s}$, followed by a melt curve using

$19795^{\circ} \mathrm{C}$ for $15 \mathrm{~s}, 60^{\circ} \mathrm{C}$ for $1 \mathrm{~min}$, and ramping $0.3^{\circ} \mathrm{C}$ from $60^{\circ} \mathrm{C}$ to $95^{\circ} \mathrm{C}$, followed by a $15 \mathrm{~s}$ hold at $95^{\circ} \mathrm{C}$.

198 All samples were run in triplicate and values presented are an average of triplicates, treating wells with

199 undetectable amplification as zero copies.

201 RESULTS

202 In order to determine the factors that affect survival of $M$. arenaria BTN cells in seawater, we collected

203 MarBTN cells from heavily neoplastic animals and incubated those cells in ASW of varying salinity, pH,

204 and temperature. Identification of dead cells is challenging in marine cells, as trypan blue (a vital

205 exclusion dye often used to identify dead cells in mammalian cell culture) precipitates out of solution

206 when prepared at salinities found in seawater. Therefore, we tested alternate vital dyes, and found that

207 erythrosine B remains in solution and functions well at salinities up at least twice marine salinity (72 g/L

208 Instant Ocean, $1.045 \mathrm{sg})$.

209 As found in the previous study of bivalve DN cells, MarBTN cells rapidly die in low salinity water

210 (Figure 1A). In contrast, the majority of cells survive at least $4 \mathrm{hrs}$ in ASW of expected marine salinity in

211 the New England area (1.023 sg). BTN cells also show the greatest survival at expected marine pH, but

212 complete cell death required highly acidic conditions not likely to be relevant to the environment (Figure

213 1B). Variation of temperature from 4 to $37^{\circ} \mathrm{C}$, in contrast, had minimal effect on survival within 4 hours

214 (Figure 1C). 
A four-hour incubation was chosen for these experiments as we found that proliferation of bacteria, protists, and unknown ciliates led to inconsistent cell survival in ASW beyond short-term incubation

217 (consistent with Sunila et al). We recently found, however, that with the use of penicillin/streptomycin

218 and notably, the addition of voriconazole, contaminant overgrowth could be controlled. We were

219 therefore able to follow MarBTN cell survival long-term. We found that cells were able to survive far 220 longer than four hours in 1× ASW, approximating typical marine conditions (Figure 2). We observed

221 some variability in survival times for cells from different donor animals, but overall, we found that cells

222 consistently survived longer at colder temperatures. At temperatures from $4^{\circ} \mathrm{C}$ to $16^{\circ} \mathrm{C}$, an average of

$223>48 \%$ of BTN cells survived for one week, and, at $4^{\circ} \mathrm{C}, 49 \%$ of cells survived for two weeks. For cells

224 from one animal, $>50 \%$ of BTN cells were still alive after one month at $4^{\circ} \mathrm{C}$ (living cells could still be

225 detected after more than 8 weeks). This dramatically increases the amount of time BTN cells are known

226 to survive in ASW, showing that BTN cells survive long enough to broadly disseminate through seawater

227 to infect other clams.

228 For BTN to be spread through the water, cells need to survive, but they also need to get into the water

229 from a diseased animal. To test whether BTN cells are released by diseased clams, we used qPCR of

230 eDNA collected from both aquaria and natural water columns in regions with endemic BTN to look for

231 two markers found only in M. arenaria BTN cells. Both cancer-specific primer pairs amplify specific

232 integration sites of the LTR-retrotransposon Steamer, found only in BTN cells (Steamer is highly

233 amplified within M. arenaria BTN cells, (23)). The cancer-HL03 primers amplify an insertion site cloned

234 previously (23), and the cancer-N1N2 primers amplify an insertion found near an ORF with high

235 similarity to the gene N1N2 (identified through preliminary analysis of MarBTN genome sequencing). As

236 a control, primers in the conserved ORF of N1N2 are used to amplify total copies of the N1N2 locus. Both

237 alleles in healthy cells amplify only with the healthy N1N2 primers, while MarBTN cells contain both the

238 normal and the cancer-associated alleles and amplify with both primers (Figure 3A-C). 
To test whether BTN-specific DNA can be released and subsequently detected in seawater, we housed one healthy and two highly neoplastic animals in separate, individual aquaria, changed the water, and then

241 after $24 \mathrm{hrs}$ collected a water sample for eDNA extraction. This was done for 3 consecutive days for each

242 animal (Figure 3D-E). The qPCR data confirm that the healthy animal releases some normal DNA and no

243 detectible BTN-specific DNA, while the heavily diseased animals release significant amounts of cancer-

244 specific DNA across all three days, although the amount does vary from one 24-hour period to the next.

245 This pattern is confirmed using the secondary HL03 cancer-specific primer set (Figure S1). Additionally,

246 we can see that the ratio of cancer-N1N2 to total-N1N2 is between $0.4-0.5$, suggesting that the majority of

247 DNA in the water from both diseased animals came from released BTN cells (the cancer cells contain

248 both an allele with the insertion and one without, so pure BTN cells have a 0.5 cancer-allele fraction).

249 The natural clam environment is far larger than a $1 \mathrm{~L}$ tank, so we next wished to test whether MarBTN-

250 specific DNA could be found in wild environments where clam populations are known to be affected by

251 endemic BTN. We chose three populations in Maine, collected surface water samples from each site,

252 extracted eDNA, and performed qPCR (Figure 3F). Due to the potential for contamination with the

253 control plasmid, only the HL03 marker was used for analysis of field samples, as this plasmid was not

254 present in the lab where eDNA was extracted. These results showed levels far lower than aquaria levels

255 with known heavily diseased animals, as expected, but we did observe MarBTN-specific amplification in

256 two of the three sub-samples from Long Cove at a level above 1 copy/reaction (with amplification

257 observed in all triplicate reactions for those two eDNA subsamples). This shows that BTN-specific DNA

258 can be found in field samples of seawater in addition to being found in more concentrated laboratory

259 conditions, again providing evidence for the hypothesized seawater-transmission of BTN.

\section{DISCUSSION}

261 This study has shown that MarBTN cells can survive for many weeks in seawater under the right

262 conditions, that they are acutely impacted by salinity but not $\mathrm{pH}$, and that they can survive longer at

263 colder environmental temperatures. We also show that eDNA from MarBTN cells can be detected in both 
aquaria and field samples, providing evidence for release of BTN cells from diseased animals for the first time. The previously proposed mechanism of transmission of BTN through seawater requires both longterm cell survival in the environment and release of BTN cells into the environment by diseased animals.

267 This study provides evidence supporting both of those requirements.

268 This study largely agrees with the findings of Sunila et al. (10), showing the strong effect of salinity, but 269 minimal effect of $\mathrm{pH}$, and minimal effect of temperature on short-term survival except for toxicity at high 270 temperatures. However, the cancer cells in the previous study demonstrated optimal survival in 10-15 ppt 271 (approximately 1.0075-1.011 sg), a salinity level that was highly toxic to the cells in this study. Notably, 272 the samples from that study were collected from northern Chesapeake Bay. In this estuary environment 273 the surface seawater was $10 \mathrm{ppt}$, whereas the samples in the current study were taken from the coast of 274 Maine, where the seawater has a much higher salinity. Sunila et al. had hypothesized an infectious cause 275 for BTN, but it had not been confirmed at the time of that study, so it is unclear whether the cancer cells 276 in that study were from the same lineage that is currently affecting New England and Prince Edward 277 Island clams. The differences between these two findings strongly suggests that there has been evolution 278 of BTN to survive in the seawater in which it must survive in order to transmit. This could represent 279 evolution of two separate lineages within different environmental conditions, or it could represent 280 divergence of a single lineage to better survive in marine vs. estuarine environments. Regardless, both 281 studies showed that cancer cells were acutely sensitive to salinities lower than $10 \mathrm{ppt}(1.0075 \mathrm{sg})$. To date, 282 no DN has been observed in freshwater environments, so low-salinity environments may provide a 283 potential "safe harbor" for bivalves, where transmissible cancer cannot survive.

284 We found clear evidence that BTN cells survive longer in the environment in colder temperatures, which may have implications for understanding the seasonality of BTN. BTN in soft-shell clams and other species have been reported to have seasonal fluctuations in prevalence $(20,24,25)$, and these results

287 suggest that transmission may be more likely in colder seasons, although there are additional unknown 288 factors, such as the effect of temperature on the progression of disease. 
A very recent study of the MtrBTN2 lineage of transmissible cancer, known to infect four Mytilus species around the world (14-16), has shown that these cancer cells also can survive for a few days in seawater

291 (26). The authors assayed cell survival at $18^{\circ} \mathrm{C}$; our results showing longer survival of MarBTN at lower

292 temperatures suggest that their finding of 6-day survival may be an underestimate. It will be interesting to

293 determine in the future whether our finding of the effects of salinity and temperature on survival are the

294 same across BTNs from different species.

295 One limitation of our study is that detection of MarBTN-specific eDNA does not confirm that live cells

296 are in the environment, only that the DNA can be detected. However, given the fact that BTN cells in

297 different animals are identical to each other, and that BTN cells can survive well in the marine

298 environment, it seems reasonable to conclude that eDNA is detecting live cells. This study provides the

299 proof of principle for an eDNA assay that can be used to determine the timing of cell release during BTN

300 progression. It can also be used to identify the presence of BTN in field samples, potentially serving as a

301 non-invasive proxy for monitoring disease in the wild and possibly reducing the requirement for more

302 invasive and expensive screening of animals for disease.

303 In this study, we show evidence supporting the long-term survival of MarBTN cells and release of

304 MarBTN cells from diseased animals. Overall, these data provide proof of principle supporting the

305 transmission of BTN through the seawater as a pathogen, and they establish new methods to investigate

306 the mechanisms of BTN survival, progression, and spread.

\section{ACKNOWLEDGEMENTS}

309 We acknowledge the assistance of David Wilson for collection of seawater samples in Maine and Bret 


\section{FUNDING INFORMATION}

313 This project was funded by support from the NIH (K22-CA226047 for MJM and T32-GM007270 and

314 T32-HG000035 for SFMH) and NSF (grants \#1849227 to SGR, 1701480 for JAFR and MJOR, and

3151950443 for SGR and MJOR).

317 SUPPLEMENTARY MATERIALS

318 Table S1. Collection information of soft-shell clams (Mya arenaria) used in this study

319 Table S2. Primers used in qPCR and cloning

320 Figure S1. Detection of MarBTN eDNA from seawater in aquaria with secondary qPCR marker

The authors declare no conflicts of interest.

FIGURE LEGENDS 
no loss during centrifugation and pipetting. For each experiment, 3-6 independent replicates using BTN cells from separate diseased clam donors were conducted (colored points), with the average shown (black points with line) and error bars showing the standard error of the mean. Identity of clam donors is listed in

337 Table S1.

Figure 2. The effect of temperature on long-term survival of MarBTN cells in artificial seawater. BTN cells were collected from three different diseased clams and incubated in ASW (1.023 sg, pH 7.93, with penicillin/streptomycin/voriconazole). For each clam, cells were incubated in $4^{\circ} \mathrm{C}, 10^{\circ} \mathrm{C}, 13^{\circ} \mathrm{C}, 16^{\circ} \mathrm{C}$, $25^{\circ} \mathrm{C}$, and $37^{\circ} \mathrm{C}$. Cell survival was monitored by resuspension and removal of an aliquot of cells, counted using erythrosine B, at 4 hrs, 1 day, 2 days, 3 days, 1 week, and weekly beyond that. Experiments were stopped when survival dropped below $10 \%$.

BTN. Representative healthy and cancerous soft-shell clams were identified $(\boldsymbol{A})$ through a screen of hemocyte morphology, and $(\boldsymbol{B})$ the diagnosis was confirmed using a qPCR analysis of genomic DNA

347 from hemocytes obtained from one of the diseased animal and the healthy animal used in the subsequent 348 eDNA experiment. $(\boldsymbol{C})$ The schematic shows the healthy N1N2 allele and the cancer-associated allele, with arrows indicating the locations of the control primers (Total N1N2, black), used to determine the total number of clam alleles, and primers specific for the clam BTN lineage (Cancer N1N2, red), used to quantify BTN DNA. For eDNA analysis $(\boldsymbol{D}-\boldsymbol{E})$, each animal was housed in a separate aquarium, and eDNA was extracted from aquaria water on 3 sequential days. $(\boldsymbol{F})$ Samples of water from sites in Maine with soft-shell clams known to have BTN were collected and eDNA was extracted. For each site, one water sample was collected and three sub-samples were extracted separately. qPCR analysis of the MarBTN-specific marker (Cancer-HL03) confirms detection of BTN DNA in the water. Copy numbers per $\mu \mathrm{L}$ DNA were converted to copies/mL, based on normalization to the total volume of water extracted.

357 The dotted line shows 1 copy/reaction. For all qPCR, each sample was run in three reactions, and the 
only if the product was detectible in all triplicate reactions. Water was used as the no template control

360 (NTC) and was undetectable in all three wells.

\section{REFERENCES}

1. Murgia C, Pritchard JK, Kim SY, Fassati A, Weiss RA. Clonal origin and evolution of a transmissible cancer. Cell. 2006;126(3):477-87. PubMed PMID: 16901782; PMCID: 2593932.

2. Rebbeck CA, Thomas R, Breen M, Leroi AM, Burt A. Origins and evolution of a transmissible cancer. Evolution. 2009;63(9):2340-9. PubMed PMID: 19453727.

3. Pearse AM, Swift K. Allograft theory: transmission of devil facial-tumour disease. Nature. 2006;439(7076):549. PubMed PMID: 16452970.

4. Murchison EP, Schulz-Trieglaff OB, Ning Z, Alexandrov LB, Bauer MJ, Fu B, Hims M, Ding Z, Ivakhno S, Stewart C, Ng BL, Wong W, Aken B, White S, Alsop A, Becq J, Bignell GR, Cheetham RK, Cheng W, Connor TR, Cox AJ, Feng ZP, Gu Y, Grocock RJ, Harris SR, sequencing and analysis of the Tasmanian devil and its transmissible cancer. Cell. leukemia in soft-shell clams. Cell. 2015;161(2):255-63. PubMed PMID: 25860608; PMCID: PMC4393529.

381 6. Barber BJ. Neoplastic diseases of commercially important marine bivalves. Aquatic Living Resources. 2004;17(4):449-66. 
7. Carballal MJ, Barber BJ, Iglesias D, Villalba A. Neoplastic diseases of marine bivalves. J Invertebr Pathol. 2015;131:83-106. PubMed PMID: 26146225.

8. AboElkhair M, Synard S, Siah A, Pariseau J, Davidson J, Johnson G, Greenwood SJ, Casey JW,

9. Oprandy JJ, Chang PW, Pronovost AD, Cooper KR, Brown RS, Yates VJ. Isolation of a viral agent causing hematopoietic neoplasia in the soft-shell clam, Mya arenaria. Journal of Invertebrate Pathology. 1981;38(1):45-51.

10. Sunila I, Farley CA. Environmental limits for survival of sarcoma-cells from the soft-shell clam Mya arenaria. Diseases of Aquatic Organisms. 1989;7(2):111-5. PubMed PMID: WOS:A1989AY90800005.

11. Moore JD. Pathogenesis of disseminated neoplasia in eastern Pacific Mytilus trossulus: University of Washington; 1993.

397 12. Metzger MJ, Villalba A, Carballal MJ, Iglesias D, Sherry J, Reinisch C, Muttray AF, Baldwin SA, Goff SP. Widespread transmission of independent cancer lineages within multiple bivalve species. Nature. 2016;534(7609):705-9. PubMed PMID: 27338791; PMCID: PMC4939143. Clams and Beyond. PLoS Pathog. 2016;12(10):e1005904. PubMed PMID: 27788268; PMCID: PMC5082865.

14. Yonemitsu MA, Giersch RM, Polo-Prieto M, Hammel M, Simon A, Cremonte F, Aviles FT, Merino-Veliz N, Burioli EA, Muttray AF, Sherry J, Reinisch C, Baldwin SA, Goff SP, Houssin cancer identified in two marine mussel species in South America and Europe. Elife. 2019;8. PubMed PMID: 31686650; PMCID: PMC6831032. 
15. Skazina M, Odintsova N, Maiorova M, Ivanova A, Vainola R, Strelkov P. First description of a widespread Mytilus trossulus-derived bivalve transmissible cancer lineage in M. trossulus itself.

16. Hammel M, Simon A, Arbiol C, Villalba A, Burioli EAV, Pepin JF, Lamy JB, Benabdelmouna Sci Rep. 2021;11(1):5809. PubMed PMID: 33707525; PMCID: PMC7970980. PubMed PMID: 34192383. PMID: 280191.

423 19. Yevich PP, Barszcz CA. Neoplasia in soft-shell clams (Mya arenaria) collected from oil-

20. Farley CA, Plutschak DL, Scott RF. Epizootiology and distribution of transmissible sarcoma in

21. Sunila I. Serum-cell interactions in transmission of sarcoma in the soft shell clam, Mya arenaria

$$
\text { L. Comp Biochem Physiol Comp Physiol. 1992;102(4):727-30. PubMed PMID: } 1355037 .
$$

22. Renshaw MA, Olds BP, Jerde CL, McVeigh MM, Lodge DM. The room temperature preservation of filtered environmental DNA samples and assimilation into a phenol-chloroformisoamyl alcohol DNA extraction. Mol Ecol Resour. 2015;15(1):168-76. PubMed PMID: 24834966; PMCID: PMC4312482. 
434 23. Arriagada G, Metzger MJ, Muttray AF, Sherry J, Reinisch C, Street C, Lipkin WI, Goff SP.

435 Activation of transcription and retrotransposition of a novel retroelement, Steamer, in neoplastic

436 hemocytes of the mollusk Mya arenaria. Proc Natl Acad Sci U S A. 2014;111(39):14175-80.

437 PubMed PMID: 25201971; PMCID: PMC4191779.

438 24. Weinberg JR, Leavitt DF, Lancaster BA, Capuzzo JM. Experimental field studies with Mya

439 arenaria (Bivalvia) on the induction and effect of hematopoietic neoplasia. J Invertebr Pathol.

440 1997;69(2):183-94. PubMed PMID: 9056469.

441 25. Leavitt DF, McDowell Capuzzo J, Smolowitz RM, Miosky DL, Lancaster BA, Reinisch CL.

442 Hematopoietic neoplasia in Mya arenaria: Prevalence and indices of physiological condition.

$443 \quad$ Mar Biol. 1990;105(2):313-21.

444 26. Burioli EAV, Hammel M, Bierne N, Thomas F, Houssin M, Destoumieux-Garzon D, Charriere 
Figure 1. The effect of salinity, $\mathrm{pH}$, and temperature on survival of MarBTN cells in artificial seawater.

A

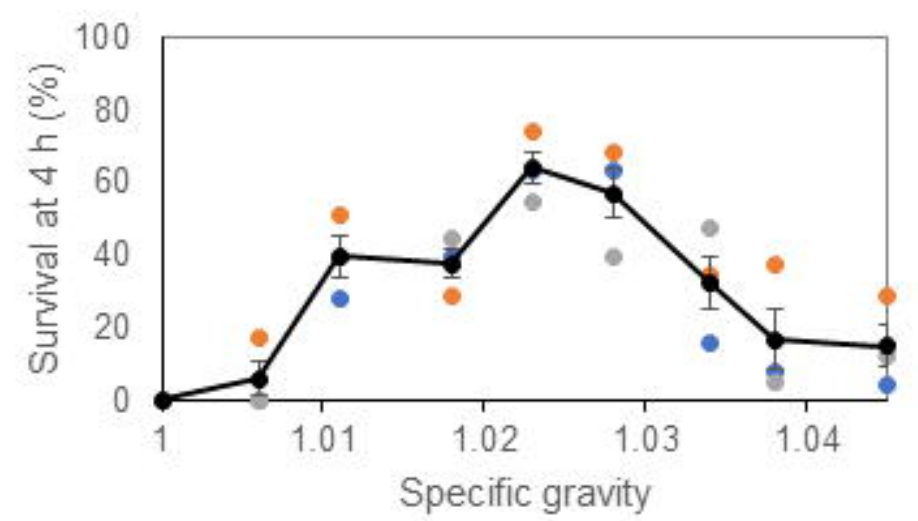

B

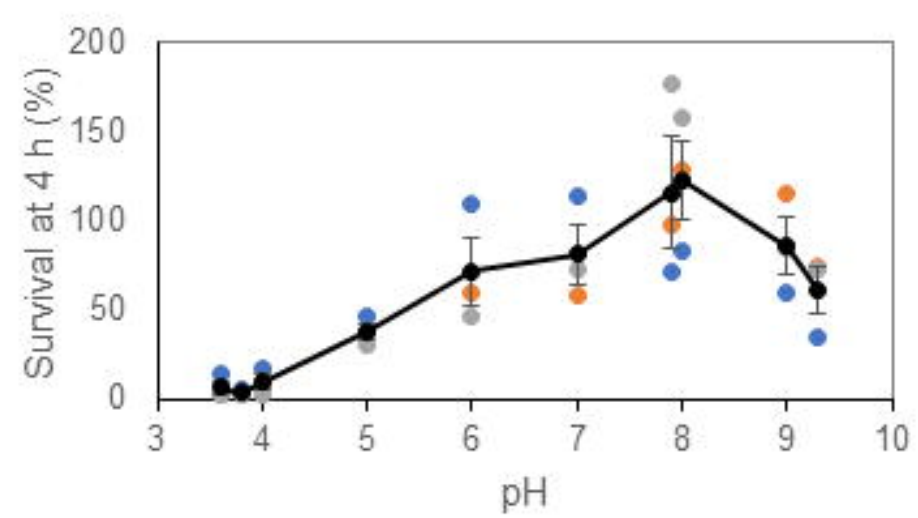

C

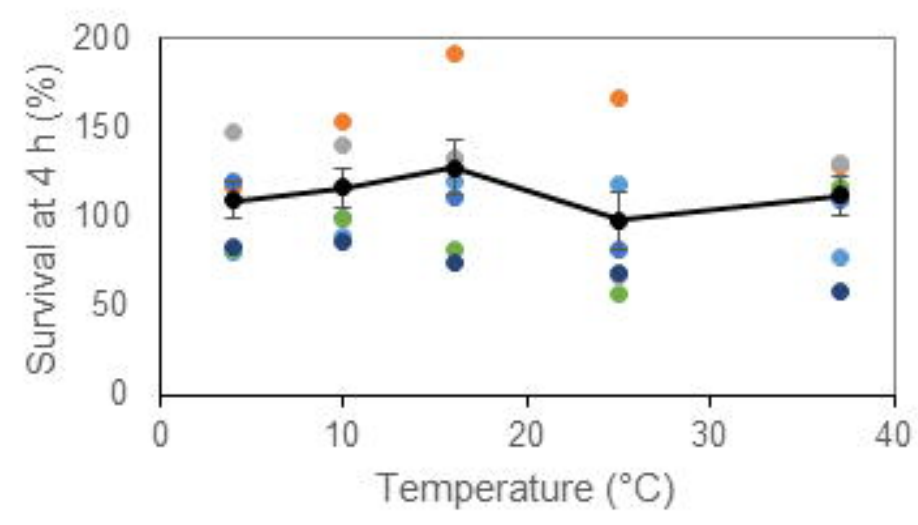


Figure 2. The effect of temperature on long-term survival of MarBTN cells in artificial seawater.
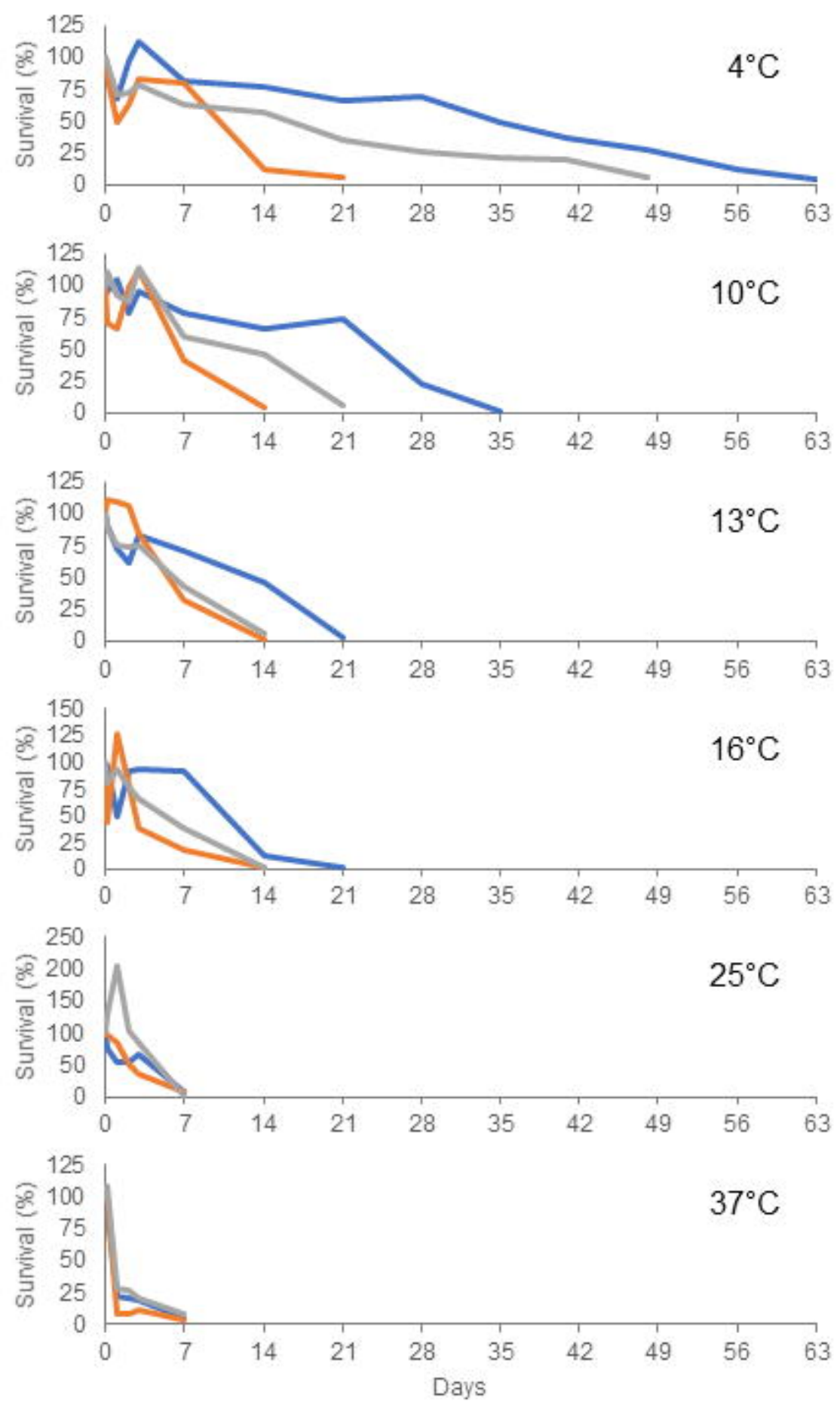
Figure 3. Detection of MarBTN eDNA from seawater in aquaria and from sites of known endemic BTN.

A

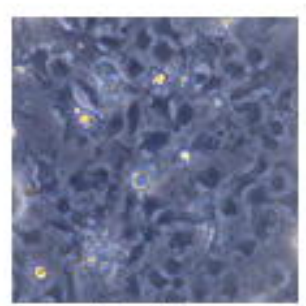

Healthy (MLN-4D6)

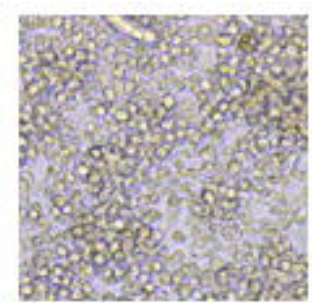

Cancer

(MLN-5D6)

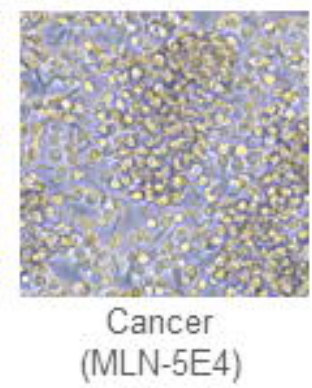

B

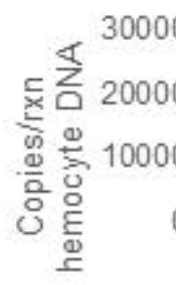

C

Healthy allele

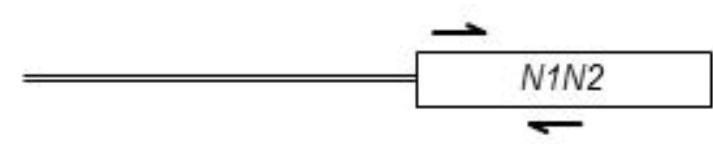

BTN-specific allele

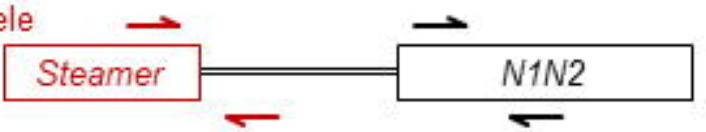

D

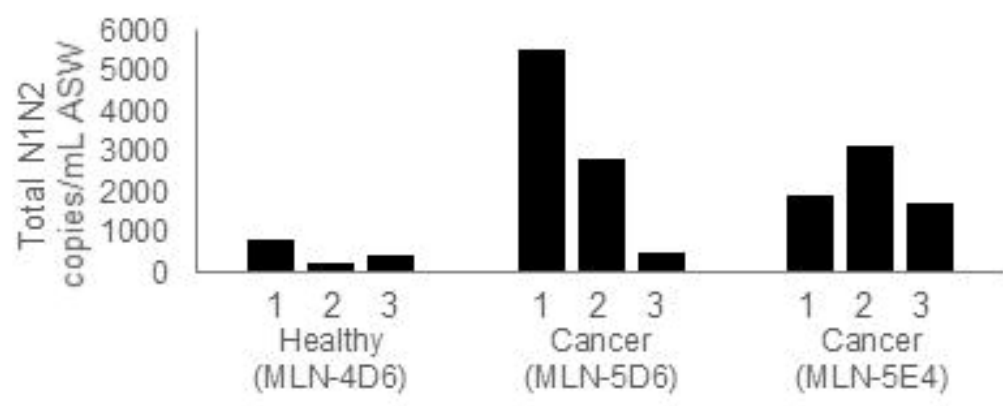

E

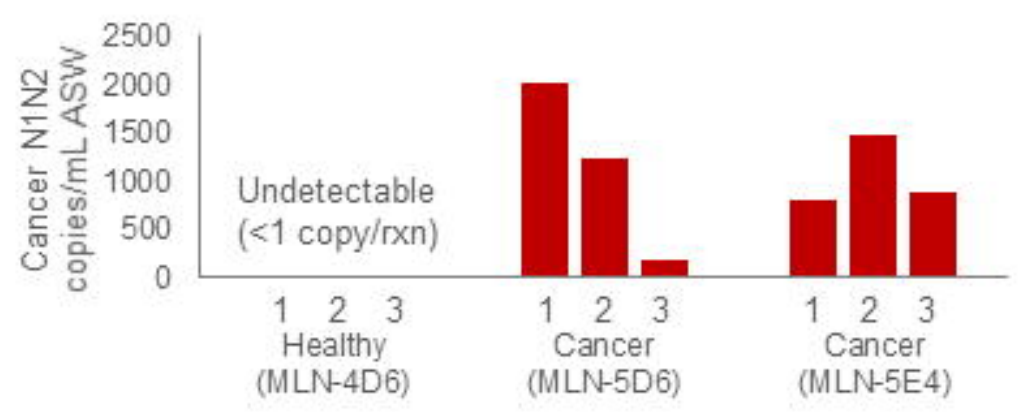

F

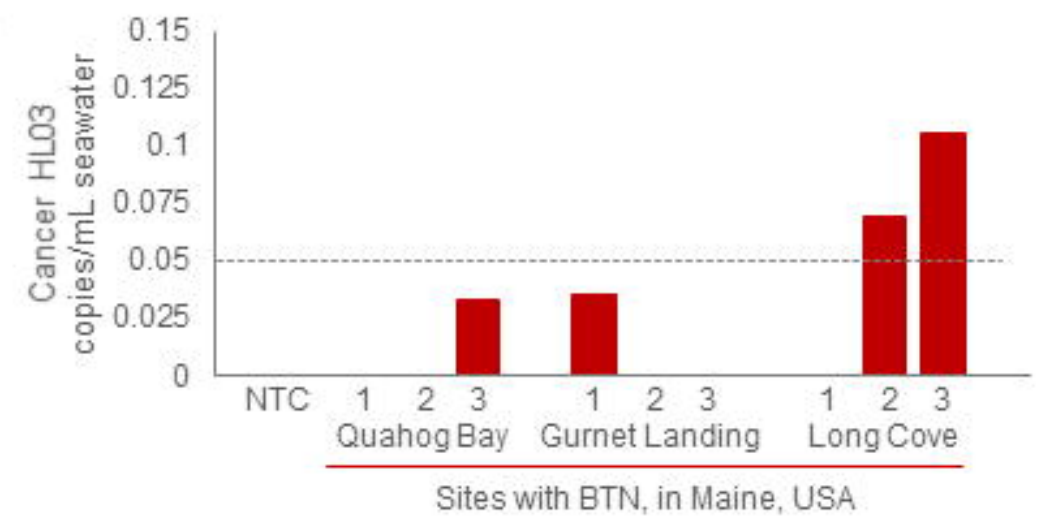

